\title{
Effect of slope on some soil characteristics at Wadi Naghamish, North Western Coast of Egypt
}

Taher M. H. Yossif and Gihan. M. Ebied ${ }^{1}$

\begin{abstract}
This study aims to assess the effect of both of aspect and slope gradient on some soil characteristics in a representative watershed in the NW coastal region of Egypt. Topsoil samples $(0-25 \mathrm{~cm})$ were collected from thirty sites approximately evenly distributed over the entire watershed; depending on a particular combination of major slope gradient and aspect of soils by using the spatial analyst function in Arc GIS software. Soil samples were analyzed for physical, chemical and nutritional routine characterizations. A factorial model on the basis of randomized complete block design was used to analyze the soil data. The results based on statistical analysis showed significant differences between soil characteristics of coastal plain (having none of both aspect and gradient) and those of other different slope aspects and gradient at 5 $\%$ level of confidence. The magnitude of some soil physicochemical characteristics and available nutrients such as clay, active calcium carbonate, $\mathrm{EC}, \mathrm{OM}$, soil $\mathrm{pH}, \mathrm{N}, \mathrm{P}$, and $K$ is significantly higher in the coastal plain soils compared to northern, eastern and western slope aspect and low, medium and high slope gradient. However, the available Fe was significantly higher in the west facing slope and high slope gradient than the other aspect and slope gradient. The differences in available nutrients of $\mathrm{Mn}, \mathrm{Zn}$ and $\mathrm{Cu}$ were not related to slope gradient across soils on all slope aspects and gradients of the study area. Also, the results showed that aspect and slope gradient had an effect on spatial heterogeneity and distribution of some soil characteristics and nutrients resources in the NW coastal region of Egypt.
\end{abstract}

Key Words: Wadi Naghamish, soil characteristics, aspect, slope gradient, spatial analyses, GIS.

\section{INTRODUCTION}

The variability of almost all soil properties is the final result of dynamic interactions among several natural environmental factors [i.e., climate, parent material, vegetation, and topography]. In general, the topography and the relief are identical terms used to mean the configuration of the land surface (Jenny, 1941). In this connection, Aandahl, (1949) stated that slope could be well identified in terms of concepts, namely aspect, gradient, length, and curvature. Birkeland (1984) added that both of aspect and slope gradient are considered having relatively higher significance with respect to many of the soil forming processes, soil erosion, and vegetation growth. He indicated that soil aspect showed a considerable effect on the microclimate that in turn influence soil organic matter and clay content as well as soil reaction and nutrient level. Furthermore, it has been indicated that north facing slopes generally are less subjected to sunlight but higher moisture levels resulting in greater vegetation cover. That is in contrast to the south facing slopes as reported by Kutiel (1992), Kutiel and levee (1999) and Marcelo and Maxim (2001). According to Rezaei and Gilkes (2005 a \& b) soil fertility, in general, is higher on north-facing slopes than those corresponding to the south-facing slopes.

Ritter (1986) postulated that difference in some soil attributes such as their richness in clay, organic matter and moisture content could be rendered to differences in slope gradient as soils associated to low slope gradient are higher in moisture content, richer in clay and organic matter content if compared with those with steeper slope gradient. According to Birkeland (1984) steep slope tend to be freely drained which is in contradiction to low slope gradient or flat soils that are usually poorly drained.

In arid region, lateral moisture transfer is relatively less than in case humid region due to the rarity of rainfall. However, there has been found increase in clay content in downslope. That could be attributed to the insitu weathering of underlying rock. He added that only easily soluble compounds of calcium, magnesium and sodium increase downslope via lateral translocation. While relatively low soluble compounds of iron, manganese, zinc and copper released by weathering would stay of release (Birkeland, 1984).

Finney et al. (1962), Fanzmerier et al. (1969), Macyk et al. (1978), Brian and Edward (1991) have demonstrated the importance of aspect and slope gradient on soil properties. Although very important, the effect of aspect and slope gradient on soil characteristics has been studied only to a limited extent. In addition, little attempt has been made to assess changes that occur in soils on different slope aspect across a slope gradient changes from gentle (1 to $3 \%$ ) to steep (30 to $60 \%$ ).

The North Western coastal region of Egypt extends $500 \mathrm{~km}$ from west of Alexandria to the Libyan border

\footnotetext{
${ }^{1}$ Dep. of Pedology, Water resources and desert land division, Desert Research Center, Cairo, Egypt.

Email: taheryossif@yahoo.com

Received November 16, 2015, Accepted December 30, 2015
} 
and is unique in similarity of its geomorphic units where mainly occupied with three geomorphic units, namely; coastal plain, piedmont plain and plateau and composed essentially of sedimentary rocks that belong to the Teriatory and Quaternary ages. The strata, from the seacoast to plateau, are formed of a calcareous formation of Pliocene and Pleistocene ages, but covered by recent aeolian and fluvial sediment. Those three geomorphic units are dissected by 218 wadis having different aspect slope and gradient. From these wadis, Naghamish wadi that faces many challenges like found in similar dry land areas of the Middle East as the area have a fragile natural resource base and offers limited alternatives for sustainable increases in agricultural productivity under rainfed conditions. According to Abdel-Kader et al. ( $\uparrow \cdots \varepsilon)$, there has been a significant increase in small ruminant population with feeding of cereal grains/concentrates encouraged by government pricing policies and subsidies and by the extension of low yielding minimal input barley cultivation into rangelands.

Because of the lack of information on soil physical, chemical properties and available nutrients content in relation to aspect and slope gradient in the North Western coastal region of Egypt, the objective of the study was to assess the effect of aspect and slope gradient on some soil characteristics of a representative watershed in the NW coastal region of Egypt. The study outputs could support sustainable land and water management in rainfed areas in Egypt.

\section{MATERIALS AND METHODS}

Wadi Naghamish is located $15 \mathrm{~km}$ east of Marsa Matrouh city and extends $20 \mathrm{~km}$ south from the coast. It is bounded by latitudes $31^{\circ} 06^{\prime}$ and $31^{\circ} \quad 16^{\prime} \mathrm{N}$ and longitudes $27^{\circ} 10^{\prime}$ and $27^{\circ} 22^{\prime} \mathrm{E}$, with a total area of about 25000 feddans, out of which more than 5000 feddans are cultivated land, (Fig. 1). The floor slopes generally downwards in the north eastern direction from $180 \mathrm{~m}$ above sea level to sea level. The climate is Mediterranean with the mean annual rainfall of about $120 \mathrm{~mm}$. Soils' parent materials have been mainly formed during Pleistocene and Holocene ages of the recent era as surficial flood sediments of a calcareous formation, EGPC- Conco Coral, (1987). The soils were classified and mapped by Abdel-Kader et al. (2004) into different sub great groups of Lithic and Typic Torripsamments, and Lithic and Typic Torriorthents.

To study the effect of aspect and slope gradient on some soil characteristics, the methodology involved the following main tasks:

Four topographic map sheets of scale $1: 50000$ were scanned and saved as raster layer in tiff-format. The raster pictures showing spot height, contour lines and other features were rectified to Universal Transverse Mercator (UTM) projection type (zone 35) with datum and spheroid of WGS84. ERDAS Imagine 9.2 software (ERDAS 2010) was used for this function.

A vector layer as shape file, containing elevation points of the study area were created by screen digitizing of the scanned topographic maps (topographic contour lines and elevations points) which merged and transformed into one mosaic map and transformed into DEM (Fig. 2) by using Inverse Distance Weighted Average interpolation method of the spatial analysis function in Arc GIS software (ESRI, 2010) to represent the study area as continuous surface showing the elevation in a digital gridded (raster) model, and to derive a detailed slope map at scale 1:50000.

The digital slope gradient (Fig. 3) and aspect (Fig. 4) maps were derived from the generated DEM by using the spatial analyst function in Arc GIS software (ESRI, 2010) of the study area. In the slope gradient map, the slope gradient was divided into four classes of slope $\%$; flat areas $(0-1 \%)$, low slope areas $(1-3 \%)$, medium slope areas $(3-5 \%)$ and high slope areas $(5-10 \%)$.

The slope map (Fig. 5) was produced by merging between digital slope gradient and digital slope aspect where each slope mapping unit is defined as a particular combination of major slope gradient and slope aspect.

Twenty seven soil sites were tested and represented by surface soil samples, Fig. (5). The investigation soil sites were selected depend on the defined slope mapping units of soils in terms of three slope aspect; named, North (N), East (E), West (W) with three slope gradient units; Low slope areas (L), Medium slope areas (M) and High slope areas $(\mathrm{H})$ with representing by three replicates. In addition, three soil sites on coastal plain (Cp) with none (of both) aspect and slope gradient were sampled to compare soil characteristics. All soil samples were collected from the upper $25 \mathrm{~cm}$ of the surface soil, where the main effects of different pedological and geomorphological process may occur.

The collected soil samples were subjected to some physical and chemical analyses using the soil survey laboratory methods manual, USDA (2014), (Table 1).

To determine quantitative effects of the aspect and slope gradient on soil characteristics, a statistical analysis for data was conducted by SPSS 21.1 software program (SPSS, 2014). A factorial model on the basis of a Randomized Complete Block Design (RCBD) was used for data analysis. Two-way analysis of variance (ANOVA) was used to test aspect and slope gradient effects on some soil characteristics. The obtained soil data on different aspect and slope gradient were compared with the obtained soil data on coastal plain. 
The differences between the means of soil characteristics were compared using least significant differences (LSD) at $p \leq 0.05$. Linear regression analysis was used to show trends, if any, between soil characteristics across varying slope gradients for different aspect in the entire watershed (Table 2).

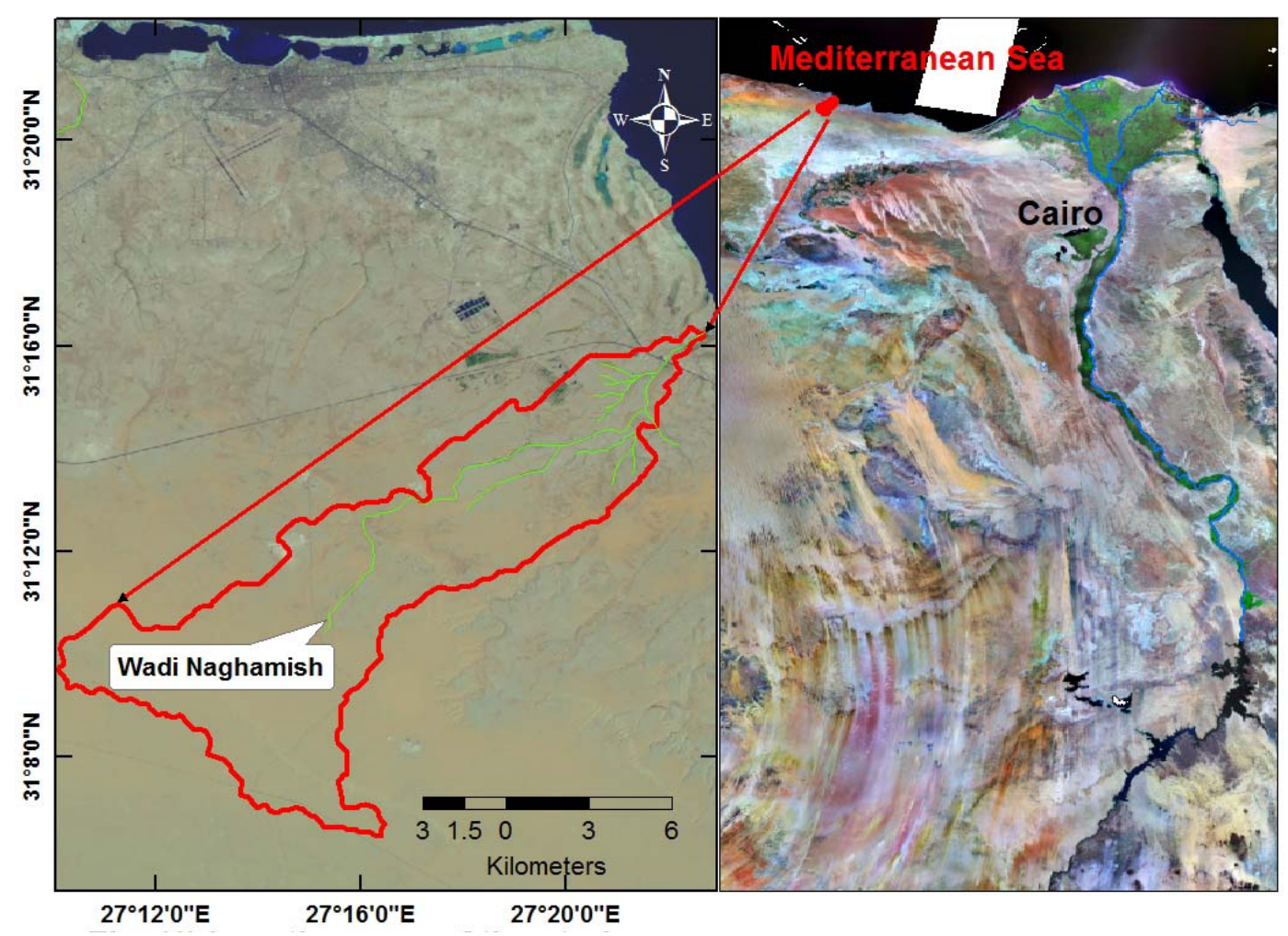

Fig. 1. Location map of the studt area.

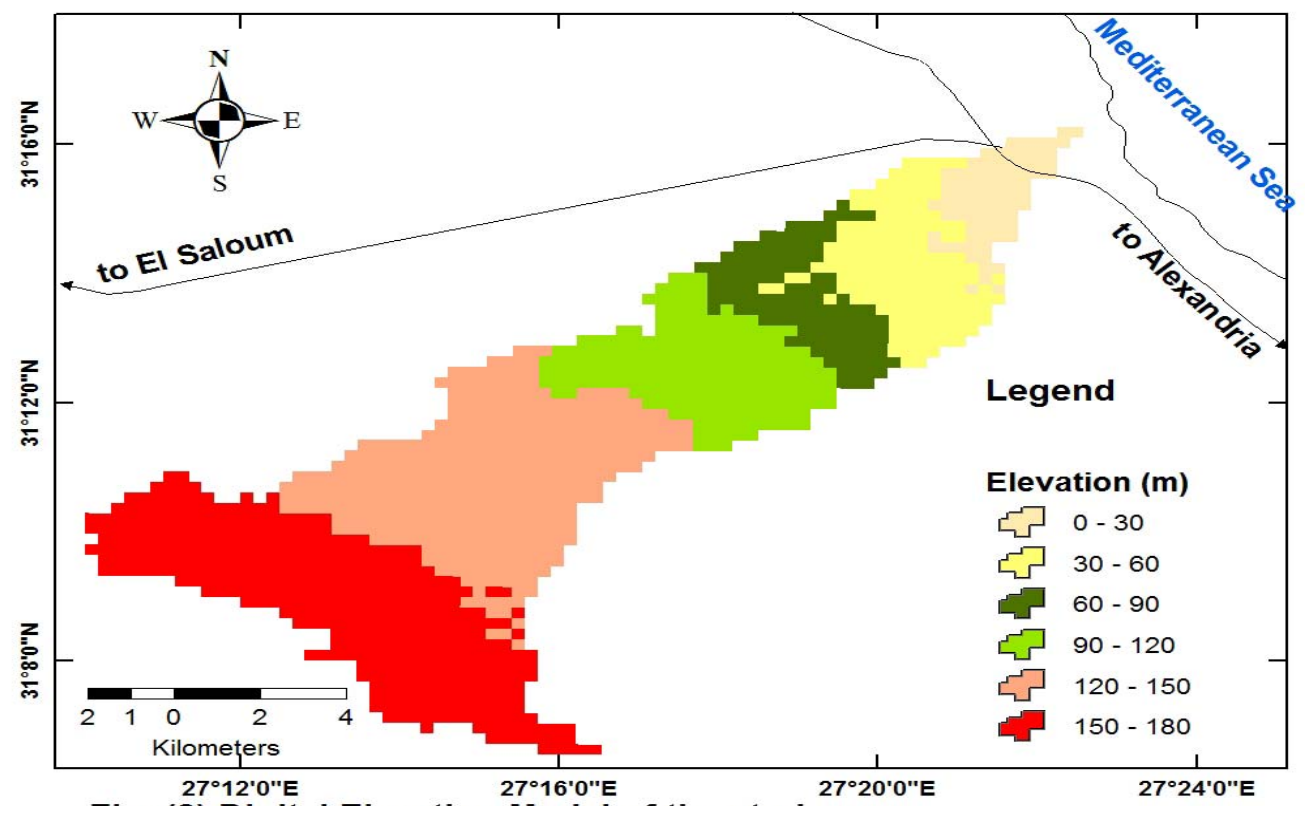

Fig. 2. Digital Elevation Model of the study area. 


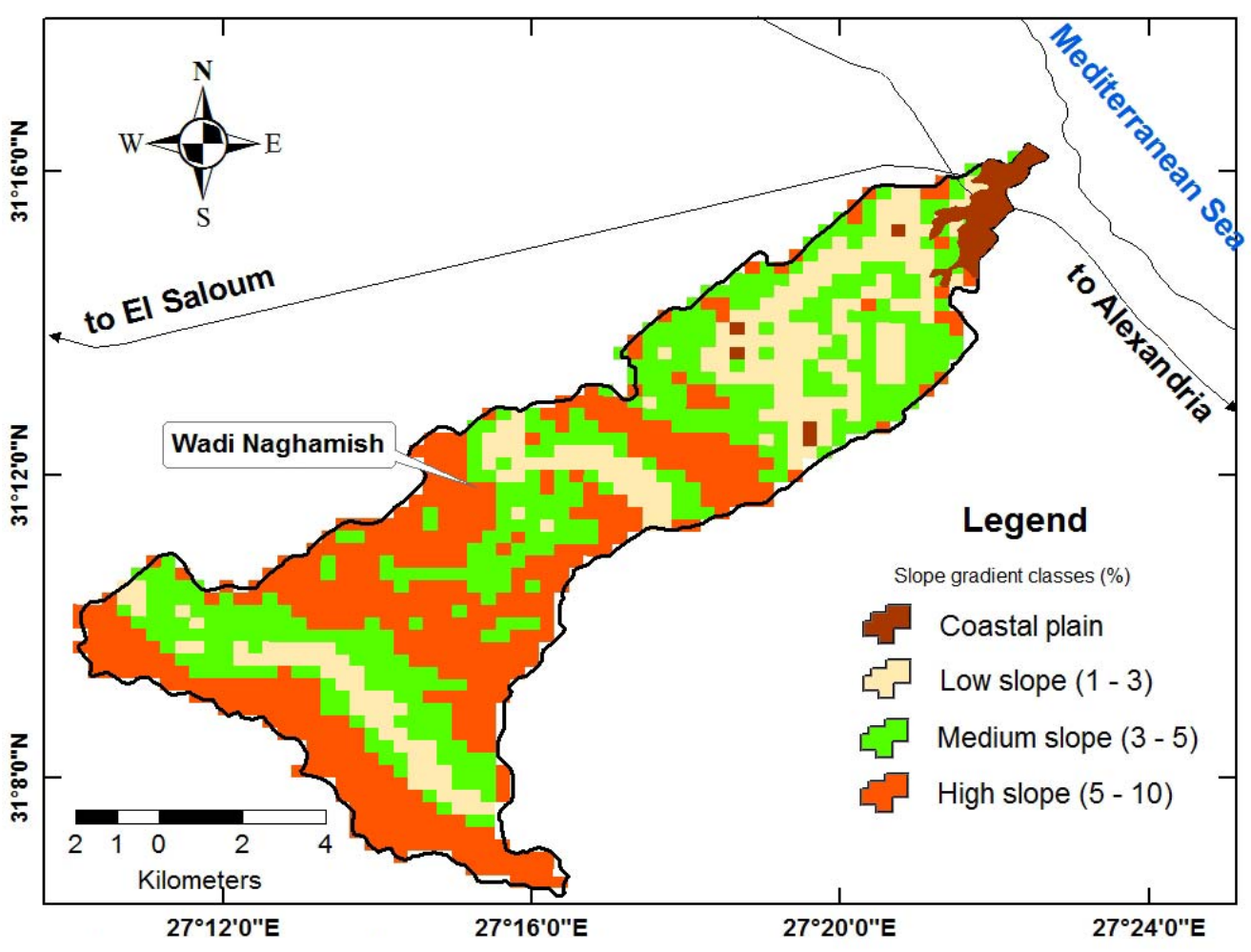

Fig. 3. Slope gradient map of the study area.

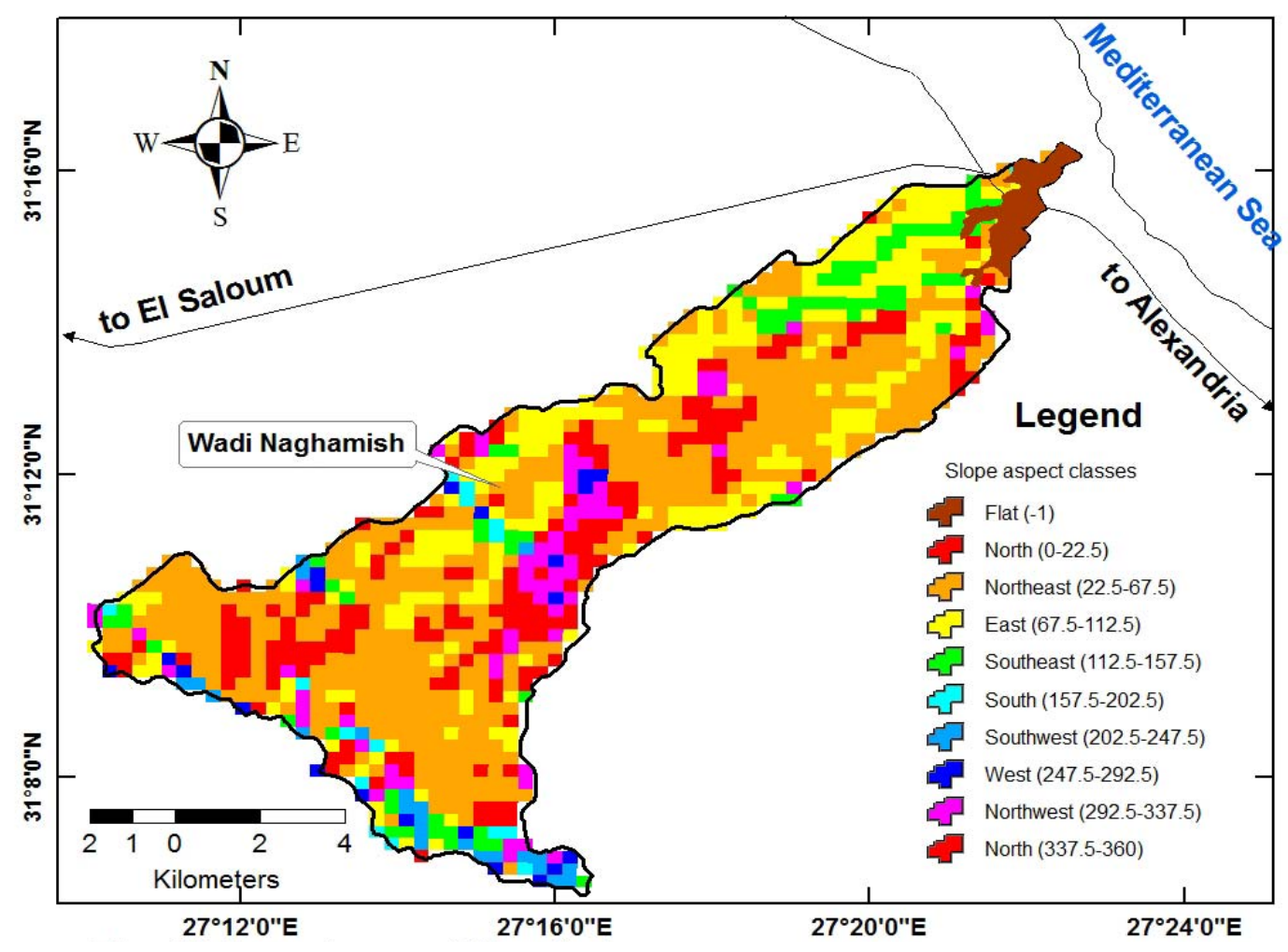

Fig. 4. Aspect map of the study area. 


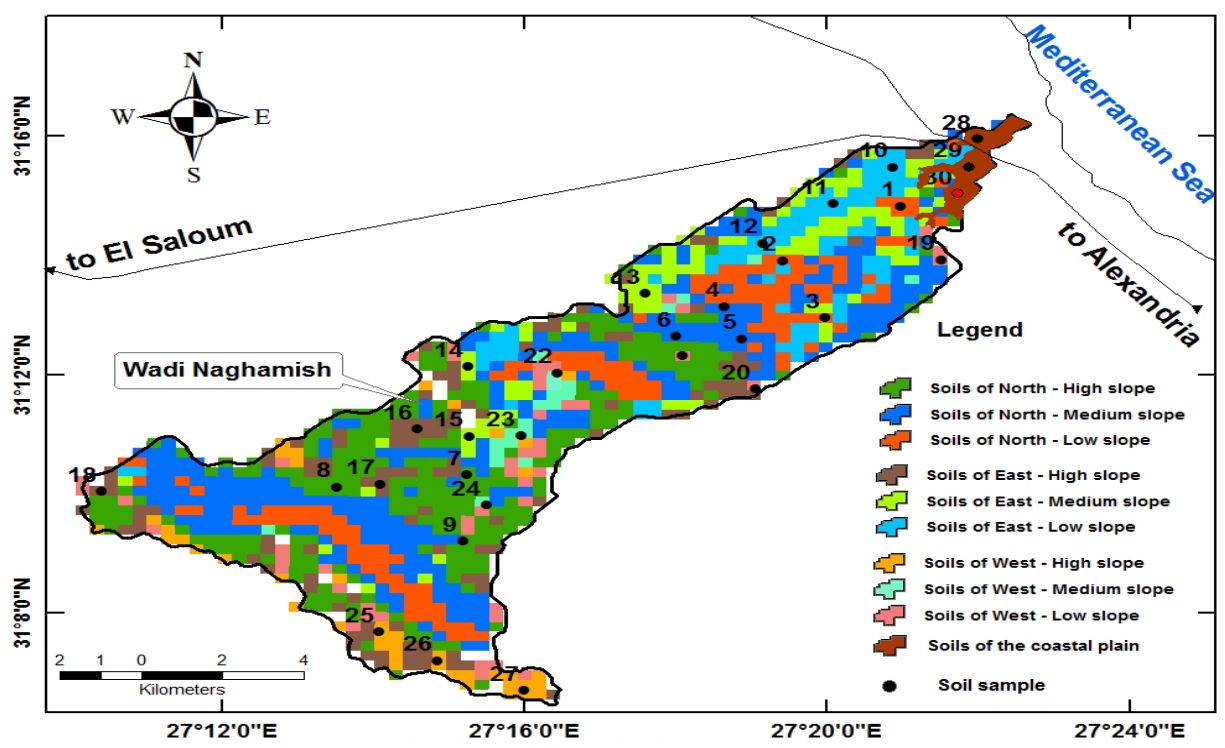

Fig. 5. The merging between slope gradient and aspect and the representative soil samples of the study area.

Table 1. Selected physico-chemical characteristics and some nutrients of the studied soils in Wadi Naghamish, North Western Coast of Egypt.

\begin{tabular}{|c|c|c|c|c|c|c|c|c|c|c|c|c|c|c|}
\hline \multirow{5}{*}{$\begin{array}{c}\text { Profile } \\
\text { No. } \\
1 \\
\end{array}$} & \multirow{3}{*}{\multicolumn{2}{|c|}{ Slope }} & \multirow{4}{*}{$\begin{array}{r}\text { Clay } \\
(\%)\end{array}$} & \multicolumn{4}{|l|}{ Active } & \multicolumn{7}{|c|}{ Available } \\
\hline & & & & \multirow{3}{*}{$\begin{array}{c}\mathrm{CaCO}_{3} \\
\%\end{array}$} & \multirow{3}{*}{$\begin{array}{r}\mathrm{pH} \\
1\end{array}$} & \multirow{3}{*}{$\frac{\mathrm{dSC}^{-1}}{2.5}$} & \multirow{3}{*}{$\begin{array}{c}\text { Organic } \\
\text { matter } \\
(\%)\end{array}$} & \multirow{2}{*}{\multicolumn{3}{|c|}{$\begin{array}{c}\text { Macrronutrients } \\
(\mathbf{p p m}) \\
\end{array}$}} & \multirow{2}{*}{\multicolumn{4}{|c|}{$\begin{array}{c}\text { Micronutrients } \\
(\mathrm{ppm}) \\
\end{array}$}} \\
\hline & & & & & & & & & & & & & & \\
\hline & \multirow{2}{*}{$\begin{array}{c}\text { Aspect } \\
\text { North } \\
\end{array}$} & $\begin{array}{c}\text { Gradient } \\
(\%)\end{array}$ & & & & & & $\mathbf{N}$ & $\mathbf{P}$ & $\mathbf{K}$ & $\mathbf{F e}$ & Mn & Zn & $\mathbf{C u}$ \\
\hline & & Low & 9.5 & 4.6 & 7.7 & 0.21 & 0.61 & 81 & 5.7 & 54 & 7.4 & 4.1 & 1.0 & 1.3 \\
\hline 2 & North & Low & 12.0 & 1.5 & 7.5 & 0.65 & 0.59 & 153 & 8.6 & 122 & 4.5 & 2.0 & 1.2 & 0.8 \\
\hline 3 & North & Low & 11.0 & 4.0 & 7.5 & 0.33 & 0.68 & 93 & 5.9 & 25 & 3.1 & 2.6 & 0.4 & 1.3 \\
\hline 4 & North & Medium & 10.0 & 4.7 & 7.7 & 0.28 & 0.72 & 51 & 7.2 & 42 & 8.2 & 2.5 & 1.1 & 1.3 \\
\hline 5 & North & Medium & 10.5 & 4.1 & 7.8 & 1.12 & 0.78 & 35 & 6.9 & 49 & 7.5 & 2.8 & 0.9 & 1.4 \\
\hline 6 & North & Medium & 7.0 & 5.4 & 7.6 & 0.25 & 0.75 & 75 & 5.0 & 68 & 8.1 & 3.3 & 0.7 & 1.4 \\
\hline 7 & North & High & 3.5 & 3.0 & 7.5 & 0.33 & 0.53 & 48 & 3.7 & 39 & 5.3 & 4.1 & 0.8 & 1.5 \\
\hline 8 & North & High & 4.0 & 4.0 & 7.5 & 0.45 & 0.65 & 30 & 5.6 & 124 & 14.9 & 2.0 & 0.9 & 0.9 \\
\hline 9 & North & High & 3.0 & 2.1 & 7.6 & 0.44 & 0.55 & 42 & 4.4 & 63 & 9.3 & 2.8 & 0.7 & 1.2 \\
\hline 10 & East & Low & 13.2 & 2.7 & 7.9 & 0.23 & 0.55 & 25 & 1.3 & 57 & 5.3 & 2.6 & 0.8 & 1.9 \\
\hline 11 & East & Low & 13.0 & 3.6 & 7.9 & 5.23 & 0.86 & 30 & 3.0 & 119 & 4.5 & 2.9 & 0.2 & 1.2 \\
\hline 12 & East & Low & 12.7 & 2.9 & 7.8 & 3.68 & 0.76 & 21 & 1.9 & 78 & 6.4 & 3.5 & 0.4 & 1.7 \\
\hline 13 & East & Medium & 10.7 & 2.6 & 7.9 & 4.72 & 0.50 & 39 & 3.6 & 129 & 10.1 & 4.7 & 0.7 & 1.8 \\
\hline 14 & East & Medium & 7.1 & 3.0 & 7.5 & 0.16 & 0.56 & 25 & 3.6 & 36 & 8.1 & 5.3 & 0.9 & 1.7 \\
\hline 15 & East & Medium & 6.2 & 2.1 & 7.9 & 0.27 & 0.54 & 36 & 2.9 & 37 & 3.5 & 3.6 & 0.5 & 1.3 \\
\hline 16 & East & High & 2.1 & 4.0 & 7.6 & 0.26 & 0.72 & 51 & 2.6 & 47 & 7.9 & 0.2 & 0.4 & 1.2 \\
\hline 17 & East & High & 3.0 & 3.8 & 7.9 & 0.26 & 0.71 & 72 & 5.4 & 21 & 10.1 & 6.1 & 1.6 & 2.0 \\
\hline 18 & East & High & 2.2 & 1.6 & 7.7 & 0.44 & 0.56 & 24 & 5.5 & 23 & 9.9 & 5.3 & 0.8 & 1.6 \\
\hline 19 & West & Low & 14.1 & 3.4 & 7.7 & 0.25 & 0.62 & 51 & 9.7 & 78 & 4.9 & 4.1 & 0.7 & 2.1 \\
\hline 20 & West & Low & 13.5 & 6.7 & 7.8 & 3.42 & 0.39 & 25 & 5.3 & 62 & 12.5 & 5.6 & 1.4 & 1.6 \\
\hline 21 & West & Low & 13.0 & 4.0 & 7.8 & 0.27 & 0.94 & 24 & 1.6 & 23 & 16.6 & 6.1 & 1.1 & 1.1 \\
\hline 22 & West & Medium & 6.2 & 5.5 & 7.8 & 0.74 & 0.40 & 66 & 4.3 & 30 & 8.2 & 4.4 & 0.8 & 1.0 \\
\hline 23 & West & Medium & 5.8 & 3.8 & 7.9 & 0.30 & 0.73 & 57 & 4.2 & 37 & 5.5 & 8.0 & 1.2 & 1.1 \\
\hline 24 & West & Medium & 4.8 & 2.8 & 8.2 & 0.32 & 0.81 & 96 & 3.5 & 33 & 8.6 & 0.7 & 1.6 & 1.0 \\
\hline 25 & West & High & 2.3 & 1.5 & 8.5 & 0.24 & 0.30 & 42 & 6.7 & 71 & 9.0 & 0.3 & 0.5 & 1.1 \\
\hline 26 & West & High & 3.5 & 1.9 & 7.8 & 0.38 & 0.64 & 57 & 1.9 & 40 & 6.0 & 8.3 & 0.9 & 2.5 \\
\hline 27 & West & High & 2.6 & 2.6 & 7.7 & 0.96 & 0.63 & 48 & 1.5 & 18 & 8.0 & 5.3 & 0.3 & 2.0 \\
\hline 28 & Plain & Flat & 14.8 & 7.1 & 8.3 & 0.29 & 0.71 & 27 & 7.9 & 42 & 2.5 & 4.6 & 1.2 & 1.5 \\
\hline 29 & Plain & Flat & 15.0 & 8.9 & 8.4 & 7.51 & 0.72 & 152 & 12.0 & 104 & 3.0 & 5.8 & 0.7 & 1.9 \\
\hline 30 & Plain & Flat & 13.9 & 5.2 & 8.5 & 1.81 & 1.05 & 138 & 8.1 & 143 & 4.1 & 3.8 & 0.6 & 0.2 \\
\hline
\end{tabular}




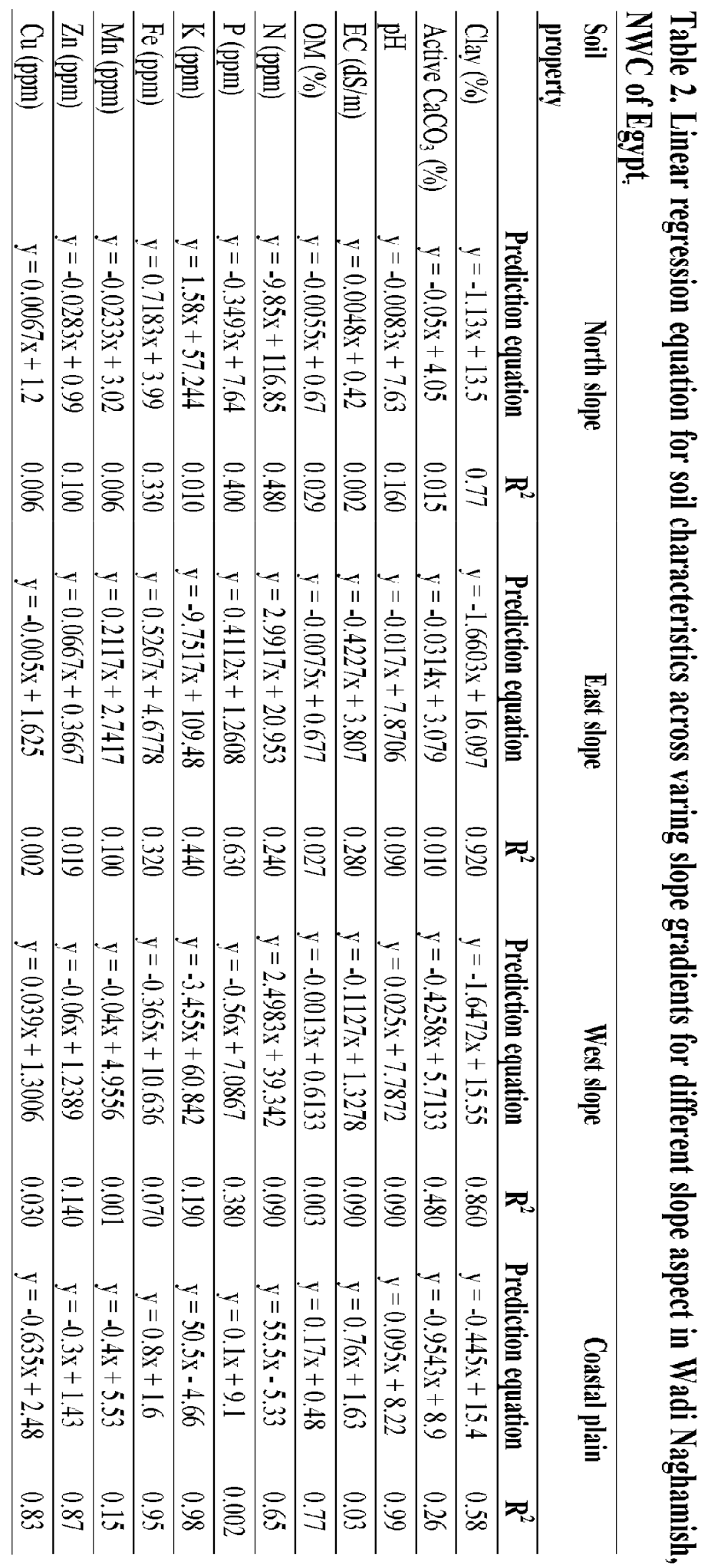




\section{RESULTS AND DISCUSSION}

\section{A- Effect of slope aspect}

The results showed significant effects of slope aspect on some soil physico-chemical characteristics and available nutrients status of the surface soil $(0-25$ $\mathrm{cm})$ at $5 \%$ level of confidence $(p<0.05)$, (Table 3$)$. In general, the soil of the study area has light or medium texture and can be classified as sandy to loamy soils. The result indicated that average amounts of the clay and active $\mathrm{CaCO}_{3}$ were highest in coastal plain with $14.56 \%$ and $7.05 \%$, respectively and significantly differed from the other aspects. No significant differences could be obtained in clay and active $\mathrm{CaCO}_{3}$ contents among the other aspect. The general content was in the order of $\mathrm{Cp}>\mathrm{N}>\mathrm{E}>\mathrm{W}$ and $\mathrm{Cp}>\mathrm{N}>\mathrm{W}>$ $\mathrm{E}$ for clay and active calcium carbonate content, respectively. This result might reflect the influence of water runoff on eroded clay particles toward down slopes. On the other hand, many other factors affect the amount of clay percentage within the same area as the amount, types and percentage of vegetation cover (Anderu et al., 1995).

Soil $\mathrm{pH}$ was found to be significantly higher in the coastal plain (Table 3) compared with other aspects with 8.41 followed by $\mathrm{W}, \mathrm{E}$ and $\mathrm{N}$ aspects with 7.91, 7.78 and 7.59 , respectively. The highest value in coastal plain might be due to the higher amount of active $\mathrm{CaCO}_{3}$ and calcareous parent material dominating the area.

The significantly highest value of EC was found on coastal plain with an average value of $3.20 \mathrm{dS} / \mathrm{m}$, while the lowest values were obtained on $\mathrm{N}$ facing slope aspect with an average $0.45 \mathrm{dS} / \mathrm{m}$, followed by $\mathrm{W}$ then E facing slope aspects with averages 0.76 and 1.69 $\mathrm{dS} / \mathrm{m}$, respectively (Table 3 ). This result might be due to the hydrological processes as leached salt and it might be related to the less drained area at the coastal plain; these results are in agreement with those reported by Birkeland (1984).

The amount of organic matter was significantly higher in coastal plain compared to the other facing slopes, with an average of about $0.82 \%$ (Table 3 ). No significant differences were found between the aspects ( $\mathrm{N}$ and $\mathrm{E}$, but with little different with $\mathrm{W}$ ), although there is a general trend in which the organic matter in the soil on the northern aspect is higher than on the eastern and western aspect (Table 3). This is consistent with the result of lower soil temperature on north facing slope than other facing slope and consequently less soil moisture evaporation, more plant growth and little organic matter mineralization, which are concurrent with the finding by Kutiel (1992), Kutiel and levee (1999), Rezaei and Gilkes (2005 a).

The soil nutritional status of the study area varied among the different slope aspects (Table 3). There were no significant differences among the aspects for nutrients concentrations of $\mathrm{Mn}, \mathrm{Zn}$ and $\mathrm{Cu}$, whereas the concentration of available $\mathrm{N}, \mathrm{P}, \mathrm{K}$, and $\mathrm{Fe}$ were significantly differed among aspects. Concentration of available N, P and $\mathrm{K}$ were higher on coastal plain (Cp) soils with averages of about 105.6, 9.3 and $96.3 \mathrm{ppm}$, respectively. These results can be explained by the effects of cultivated plants input litter via OM. In addition, Rezaei and Gilkes (2005 a) found that there is a positive correlation between soil organic matter and the capacity of the soil to supply essential plant nutrients including nitrogen phosphorus, and potassium, that may explain the significant higher soil nitrogen, phosphorus, and potassium at the coastal plain soils and north aspect than that at the other aspect. Available Fe concentration was significantly higher in the E, W and $\mathrm{N}$ aspects compared with $(\mathrm{Cp})$. The lowest value was obtained on $(\mathrm{Cp})$ soils with $5.6 \mathrm{ppm}$. This is consistent with the effect of higher $\mathrm{pH}$ in soils of coastal plain.

\section{B- Effect of slope gradient}

The effect of slope gradient on some soil physicochemical characteristics and available nutrients status of the surface soil $(0-25 \mathrm{~cm})$ was significant differences at $5 \%$ level of confidence $(p<0.05)$, (Table 4$)$. The results revealed that clay content were gradually decreased with increasing slope gradient for the N, E and $\mathrm{W}$ slope aspect. This is due to the selectivity process during water erosion where fine particles such clay have been carried away toward the low slope and coastal plain. Average content of active $\mathrm{CaCO}_{3}$ tends to increase with down slope and it varied from 1.48 to $8.8 \%$ with an average of about $3.7 \%$ of the samples.

Soil $\mathrm{pH}$ had the highest value in coastal plain with 8.4 and it significantly differed from the other slope gradients. No significant differences were obtained in $\mathrm{pH}$ values between other slope gradients. Values of $\mathrm{pH}$ were in the order of $\mathrm{Cp}>\mathrm{M}>\mathrm{H}>\mathrm{L}$. Similar results were obtained by Khormali et al. (2007).

The lowest EC value was obtained on $\mathrm{H}$ slope gradient $(0.41 \mathrm{dS} / \mathrm{m})$, which was significantly differed from the $\mathrm{M}, \mathrm{L}$ slope gradients and coastal plain area with values of $0.9,1.58$ and $3.2 \mathrm{dS} / \mathrm{m}$, respectively. The relatively high EC detected especially in coastal plain area (Table 3 and 4), due to input of sediment received from upper slopes. Also, saline soils are found in the less drained area at the bottom, while soils on high slope gradients undergo more leaching (Birkeland, 1984). 

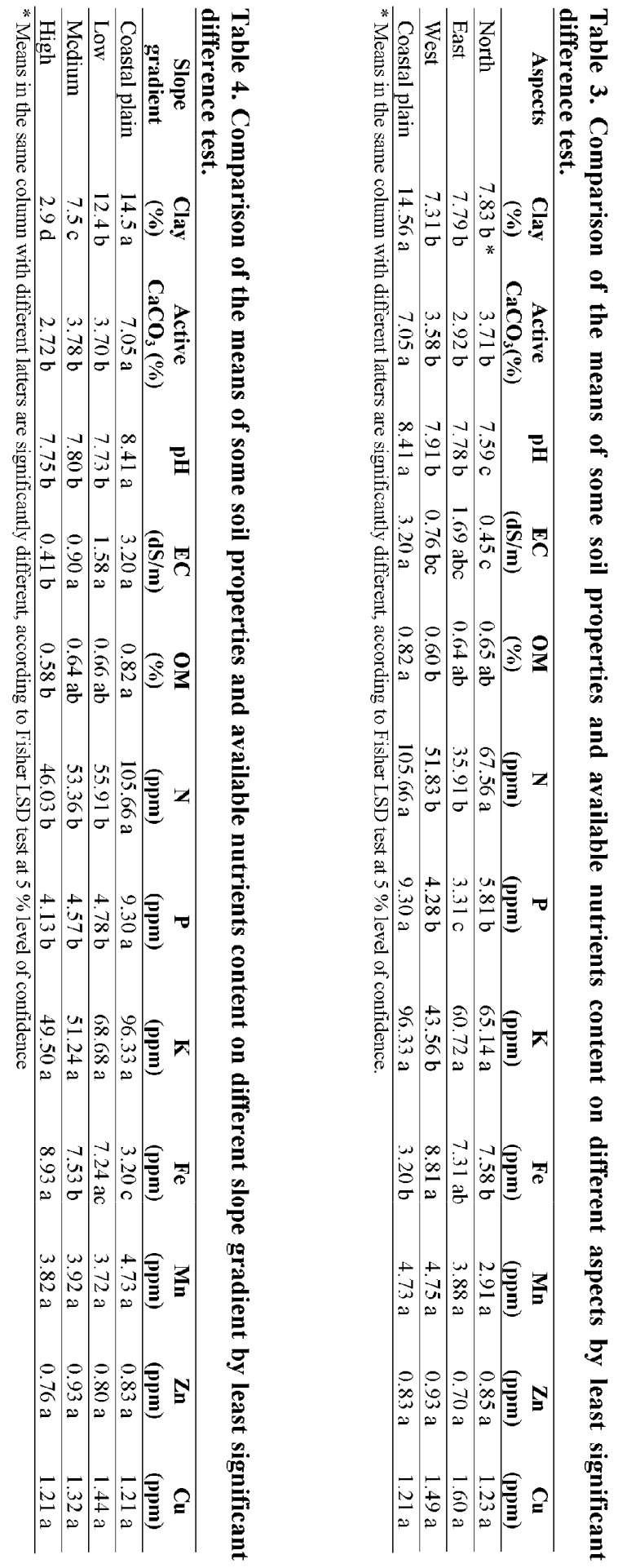
The organic matter content of the studied soils was significantly highest on the coastal plain, compared with the other slope gradients. It also was decreased with increasing slope gradient of soils; ranging from 0.3 to $1.05 \%$. The lowest OM was found on the high slope gradient with an average of about $0.58 \%$ (Table 3), followed by $\mathrm{M}$ then $\mathrm{L}$ then $\mathrm{Cp}$ with $0.64,0.66$ and 0.82 $\%$, respectively. Wilding et al. (1982) explains the higher organic matter of the lower slope gradient by the finer soil texture and therefore higher moisture reserved in the soil that promotes vegetation growth and reduces the oxidation of organic matter. Another reason for the higher organic matter content of the lower slope gradient is the depositions from upper positions. Brubaker et al. (1993) showed the decrease in the clay and organic matter in the lower slope gradient. Cheng (1987) however, reports that erosion of the material from upper slope gradient and their subsequent deposition in the lower positions is responsible for the higher organic matter in the lower positions. In the present study, the organic matter content in both of the coastal plain and low slope gradient was relatively higher mainly due to the higher input of organic matter from residues of cultivated plants such as Olive and Fig trees and the more dense rooting systems.

As for the effect of slope gradient on soil nutrients status, Table (4) showed that the soil on high slope gradient had relatively low available nutrient concentration than low slope gradient as a result of erosion of soil on high slope gradient and subsequent deposition on lower slope gradients. This emphasized a close relationship exists between both organic matter and the released nutrients. Such trend is greatly related to soil organic matter and clay content, taking into consideration the noticeable slope gradients. Generally, the soil of low slope and coastal plain soils have a relatively high content of the available nutrients under study as compared to the soils on the high slope of piedmont plain and plateau units.

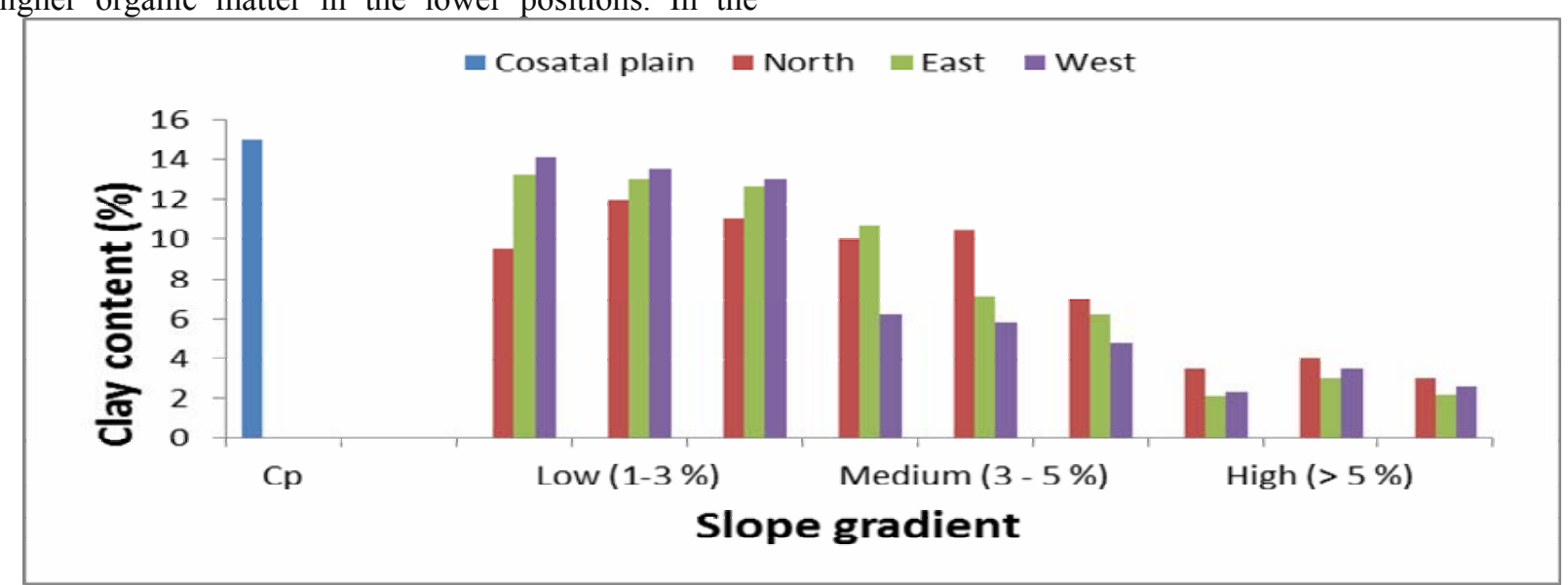

Fig. 6.Clay content for varying slope gradients on different slope aspects of the study area.

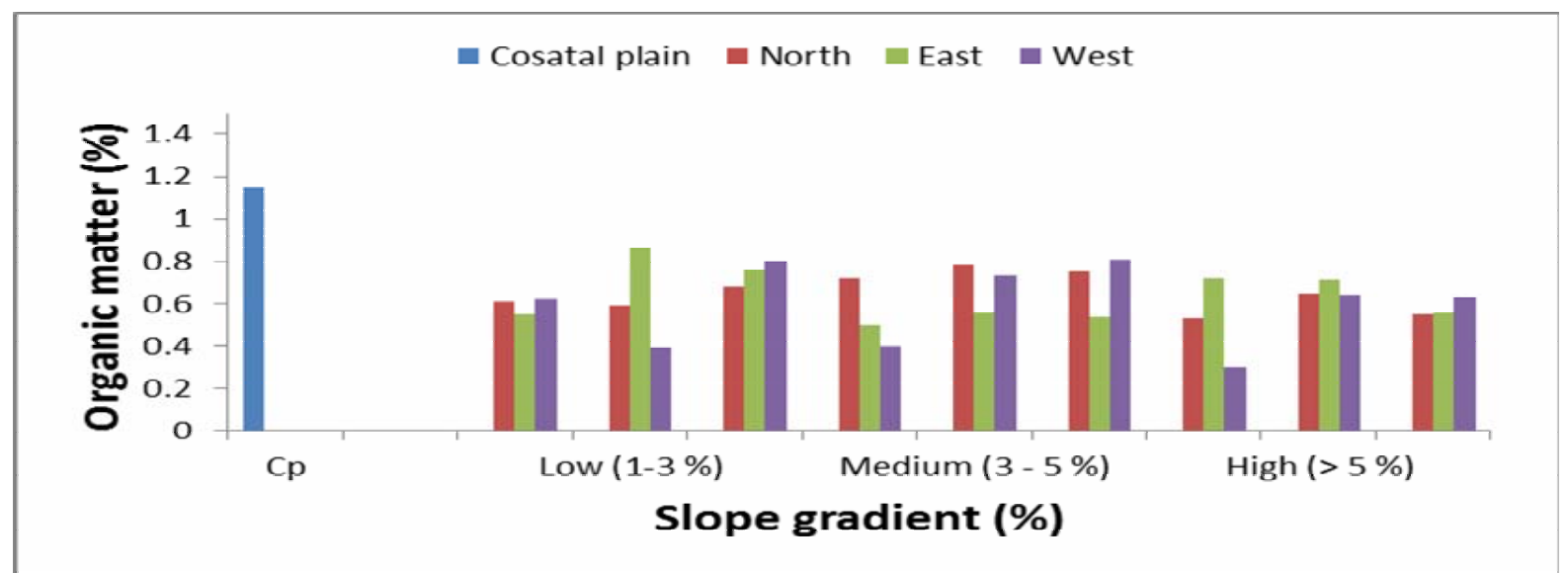

Fig. 7. Organic matter content for varying slope gradients on different slope aspects of the study area. 


\section{C- Topsoil Development}

The decrease in clay and OM content which are considered as relative indicators to the intensity of the topsoil development indicated a decrease in soil development with increasing slope gradient for different slope and aspect in the entire watershed (Table 2, Figs.6, and 7). This situation can be interpreted on bases of fact that the more slope gradient, the more soil erosion, the less infiltration and a little clay content are expected. Lateral movement of soil water across soil horizons may also occur and cause a decrease in clay content of surface soil with increasing slope gradient.

\section{CONCLUSIONS}

In this research, aspect and slope gradient affected some soil characteristics. For instance, an increasing slope gradient influenced almost all soil physicochemical characteristics and available nutrients in the surface soil $(0-25 \mathrm{~cm})$. In addition, lower soil temperature and less moisture evaporation at the coastal plain soils and on north facing slopes resulted in less organic matter decomposition and consequently more organic matter and total nitrogen accumulation in soil. Consequently, the soil nutrient and general fertility at the coastal plain soils and north-facing slope aspects were greater than other facing slope aspects. Soil erosion processes by water as well as slope aspects and gradients are most likely responsible for effect on soil physical, chemical characteristics, and available nutrients content at the same time in relation to slope aspect and gradients. Therefore, it is essential to recognize the effects of the most important component of slope on soil characteristics and in turn their effects on soil development in a native rangeland.

\section{REFERENCES}

Aandahl, A.A. 1949. The characterization of slope positions and their influence on the total nitrogen content of a few virgin soils of western Iowa. Soil Sci. Soc. Am. Proc., 13: 449-454.

Abdel-Kader, F.H., J. FitzSimon, M. Bahnassy, and A. Moustafa. 2004. Challenges in resource management in rainfed agriculture in wadi Naghamish, North Western coastal region, Egypt. Egyptian j. of Desert Res., 54, No $2,237-258$.

Andreu, V., L.L. Rubio, and R. Cerni. 1995. Effect of Mediterranean shrub on water erosion control. Environmental Monitoring and Assessment. 37: 5-15.

Birkeland, P. W. 1984. Soils and Geomorphology. Oxford University Press, NY. Pp 448.

Brian, J.C, and J.C. Edward. 1991. Slope gradient and aspect effects on soils developed from sandstone in Pennsylvania. Geoderma 49: 199-213.
Brubaker, S.C., A.J. Gones, D.T. Lewis, and K. Frank. 1993. Soil properties associated with landscape position. Soil Sci. Soc. Am. J. 57, 235-239.

Cheng, Y. 1987. Remote sensing of iron enriched paleosols in the Eastern Palouse Region. M.Sc. thesis. Washington Stat Unit., Pullman, WA.

EGPC - Conco Coral. 1987. Geological Map of Egypt, sheet of Matroh, Scale $1: 500000$.

ERDAS, Inc. 2010. ERDAS Field Guide (ERDAS Imagine).Eight Edition. Atlantic, Georgia, USA.

ESRI. 2010. Arc GIS Spatial Analyst: Advanced-GIS Spatial Analysis Using Raster and vector data, ESRI, $380 \mathrm{New}$ york, USA.

Finney, H.R., N. Holowaychuk, and M.R. Heddleson. 1962. The influence of microclimate on the morphology of certain soils of the Allegheny Plateau of Ohio. Soil Sci. Am. Proc., 26:287-292.

Franzmeier, D.P., E.J. Pederson, T.L. Longwell, J.G. Byrne, and C.J. Losche. 1969. Properties of some soils in the Cumberland Plateau as related to slope, aspect, and position. Soil Sci. Soc. Am. Proc., 33: 755-761.

Jenny, H. 1941. Factors of Soil Formation: A System of Quantitative Pedology/ By Hans Jenny. McGraw-Hill, New York.

Khormali, F., Sh. Ayoubi, F. Kananro Foomani, A. Fatemi, Kh. Hemmati. 2007. Tea yield and soil properties as affected by slope position and aspect in Lahijan area, Iran. International Journal of Plant Production. 1: pp. 98 111.

Kutiel, P. 1992. Slope aspect effect on soil and vegetation in Mediterranean ecosystem. Israel Journal of Botany. 41:243-250.

Kutiel, P., and H. Lavee. 1999. Effect of slope aspect on soil and vegetation properties along an aridity transect. Israel journal of plant science. 47:169-178.

Macyk, T.M., S. Pawluk, and J.D. Lindsay. 1978. Relief and microclimate as related to soil properties. Can. J. Soil Sci., 58: 421- 438.

Marcelo, S., and S. Maxim. 2001. Influence of slope aspect on Mediterranean woody formation: Comparison of semiarid and an arid site in Israel. Ecology Research. 16:335-343.

Rezaei, S., and R. Gilkes. 2005 a. The effects of landscape attributes and plant community on soil chemical properties in Rangelands. Geoderma .125: 167- 176.

Rezaei, S., and R. Gilkes. 2005 b. The effects of landscape attributes and plant community on soil physical properties in Rangelands. Geoderma.125:145- 154.

Ritter, D. F. 1986. Process Geomorphology, Second Editiation, Wm. C. Brown Publishers. Dubuque, Iowa.

SPSS. 2014. SPSS Base 21.1 for Windows User's Guide. SPSS Inc., Chicago IL 
USDA, Soil Survey Staff. 2014. Kellogg Soil Survey Laboratory Methods Manual. Soil Survey Investigations Report No. 42, Version 5.0. R. Burt and Soil Survey Staff (ed.). U.S. Department of Agriculture, Natural Resources Conservation Service.
Wilding, N.E., A. Smeck, and G.F. Hall. 1982. Pedogenesis and soil taxonomy. II. The soil orders. Developments in soil science.

\section{الملغص الهرب}

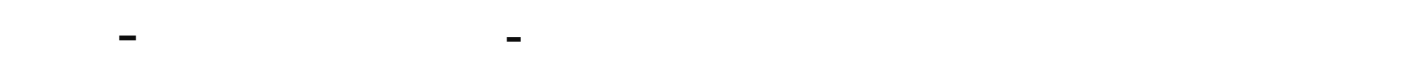 \\ طاهر مصطف حلمد يوبف وجيهان محمد عبيد لوفي}

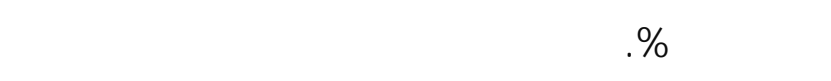

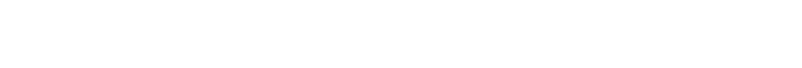

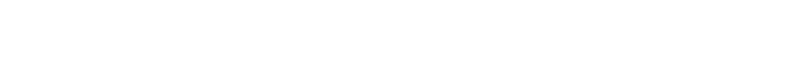

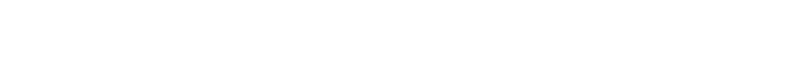

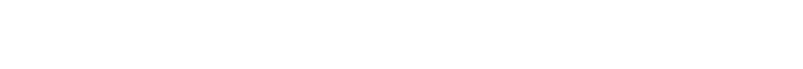

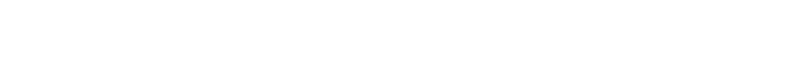

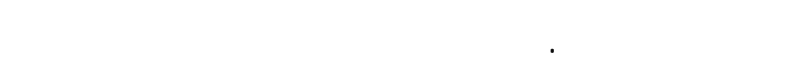

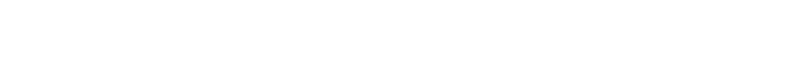

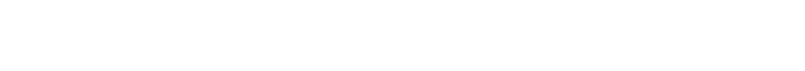

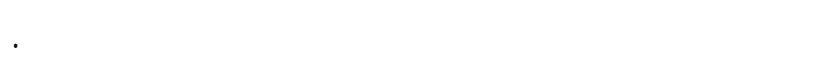

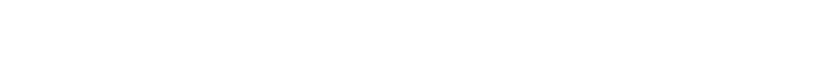

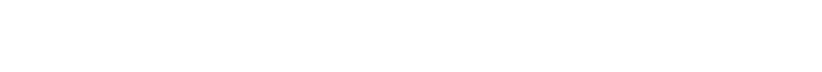
التربة على אل الإتجاهات ودرجلت الإنحدار لمظقة الإنة الدرلسة. ولظٔهرت النتائج أن التجاهلت ودرجات الأن الإنجار الإنحدار

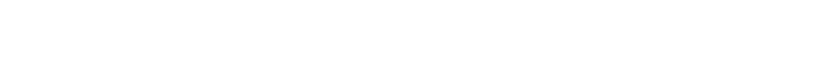
التربة الغذائية فى اقليم اللسلط اللثمالى الغربى المصر.
الهوف من إجراء هذه الدرلسة هو نقيم تأثير التجة

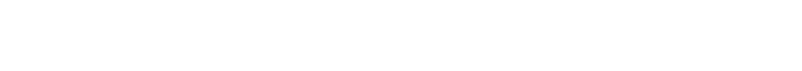

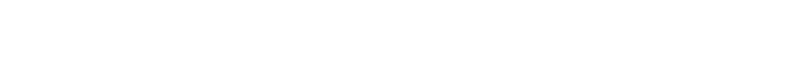

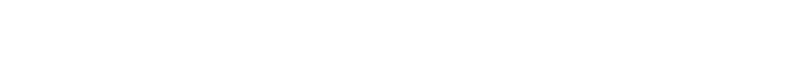

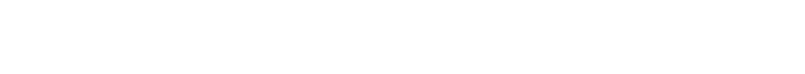

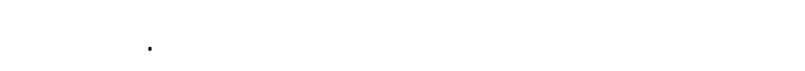

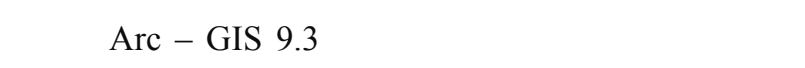

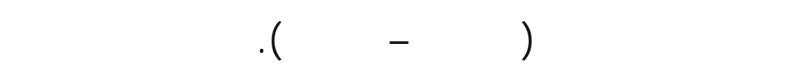

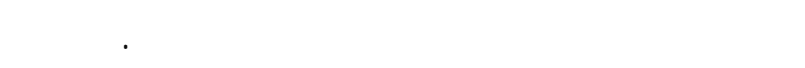

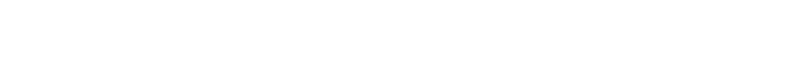
التطاعات الكلملة العشوائية لإجراء التحليل الإحصائى

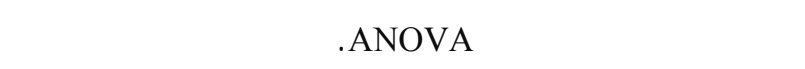

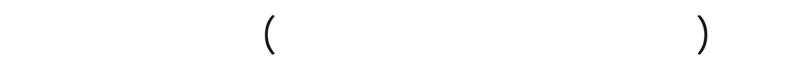

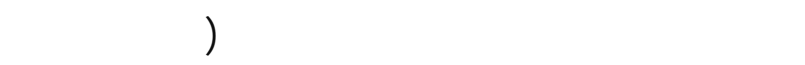

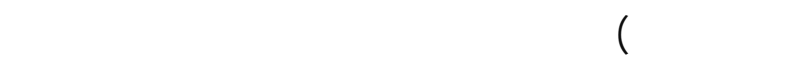

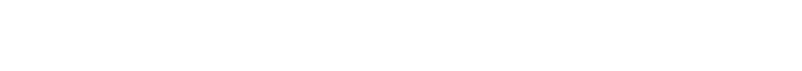

